\title{
Effect of Direct Contact on the Phytotoxicity of
}

\section{Silver Nanomaterials}

\author{
Danielle E. Gorka ${ }^{1,2}$, Jie Liu ${ }^{1,2} *$ \\ 1 Center for the Environmental Implications of NanoTechnology (CEINT), Duke \\ University, P.O Box 90287 Durham, NC, 27708, USA \\ 2 Department of Chemistry, Duke University, Durham, NC, 27708, USA \\ *Corresponding author Liu address: 124 Science Drive, Department of Chemistry, Duke \\ University, Durham, NC 27708, email: jliu@duke.edu; phone (919) 660-1549; fax (919) \\ $660-1605$ \\ KEYWORDS \\ silver nanoparticles, nanocubes, nanowires, environmental toxicity, antibacterial
}


Experimental Methods

Retention of $\mathrm{Ag}^{+}$on $3 \mathrm{kDa}$ MWCO Dialysis Membrane

To determine how much $\mathrm{Ag}^{+}$was retained on the $3 \mathrm{kDa}$ MWCO dialysis membrane, a $20 \mathrm{~mL} 100 \mathrm{ppb} \mathrm{Ag}^{+}$(from $\mathrm{AgNO}_{3}$, Aldrich, 99.9999\%) solution in Picopure water (18 M $\Omega$, Hydro Picopure UV Plus, Durham, NC, USA) with $2 \% \mathrm{NaNO}_{3}$ was prepared. The amount of $\mathrm{Ag}^{+}$was measured using a Thermo Orion silver/sulfide ion specific electrode (ThermoFisher, Waltham, MA, USA) filled with Optimum Results C Electrode Filling Solution (ThermoFisher). The $100 \mathrm{ppb} \mathrm{Ag}^{+}$solution was then passed through a rinsed and hydrated dialysis membrane (Spectra/Por 3, 3.5 kDA MWCO, Rancho Dominguez, CA, USA) using vacuum filtration. The filtrate was collected and the amount of $\mathrm{Ag}^{+}$was measured using the silver/sulfide ion specific electrode.

Calibration curves were made at the time of measurement using freshly prepared $\mathrm{AgNO}_{3}$ standards. Triplicate measurements were performed

\section{Results and Discussion}

Retention of $\mathrm{Ag}^{+}$on $3 \mathrm{kDa}$ MWCO Dialysis Membrane

The retention of $\mathrm{Ag}_{+}$on the dialysis membrane was measured to determine if ionic silver could pass through the membrane, and that membrane retention would not significantly reduce the amount of $\mathrm{Ag}^{+}$. It was determined that approximately $13 \%$ of the $100 \mathrm{ppb} \mathrm{Ag}^{+}$solution was retained on the dialysis membrane. As such a small amount of $\mathrm{Ag}^{+}$was retained, the dialysis membrane was used in further plant growth studies. 